\title{
Job Satisfaction among Practicing Pharmacists: A Rasch Analysis
}

\author{
Patrick Hardigan \\ Nova Southeastern University, patrick@nova.edu \\ Manuel J. Carvajal \\ Florida International University, cmanuel@nova.edu
}

Follow this and additional works at: https://nsuworks.nova.edu/ijahsp

Part of the Medicine and Health Sciences Commons

\section{Recommended Citation}

Hardigan P, Carvajal MJ. Job Satisfaction among Practicing Pharmacists: A Rasch Analysis. The Internet Journal of Allied Health Sciences and Practice. 2007 Oct 01;5(4), Article 11.

This Manuscript is brought to you for free and open access by the College of Health Care Sciences at NSUWorks. It has been accepted for inclusion in Internet Journal of Allied Health Sciences and Practice by an authorized editor of NSUWorks. For more information, please contact nsuworks@nova.edu. 


\title{
Job Satisfaction among Practicing Pharmacists: A Rasch Analysis
}

\begin{abstract}
Purpose: through the application of a Rasch rating scale model, the researchers investigated the effect of gender, ethnicity, practice site, income, and age on levels of job satisfaction among practicing pharmacists. Method: The data consist of responses to a survey questionnaire mailed to a random sample of 5,000 registered pharmacists throughout the United States. A total of 820 individuals mailed back their completed form for a response rate of 16.4 percent. Results: Older, higher-wage earning pharmacists working at independent practice sites experience the greatest amount of job satisfaction.Conclusion: The most significant finding from this study is that age, income, and practice site can predict job satisfaction among practicing pharmacists. Additionally, the results provide empirical evidence for the variables inclusion in future models and they demonstrate the usefulness of Rasch techniques.
\end{abstract}

\author{
Author Bio(s) \\ Research Interests: \\ Human capital \\ Pharmacist workforce \\ Gender, ethnic, and age-group comparisons \\ Cultural diversity
}




\title{
IJIAHSP \\ The Internet Jourfal of Allied Health Sciences and Practice \\ http://ijahsp.nova.edu
}

A Peer Reviewed Publication of the College of Allied Health \& Nursing at Nova Southeastern University

Dedicated to allied health professional practice and education

http://ijahsp.nova.edu Vol. 5 No. 4 ISSN 1540-580X

\section{Job Satisfaction Among Practicing Pharmacists: A Rasch Analysis}

\author{
Patrick Hardigan, PhD \\ Manuel Carvajal, $\mathrm{PhD}$
}

1. Executive Director, Testing and Evaluation, Nova Southeastern University

2. Professor of Economics, Florida International University

CITATION: Hardigan, P., Carvajal, M. Job Satisfaction among Practicing Pharmacists: A Rasch Analysis. The Internet Journal of Allied Health Sciences and Practice. Oct 2007, Volume 5 Number 4.

\section{ABSTRACT}

Purpose: through the application of a Rasch rating scale model, the researchers investigated the effect of gender, ethnicity, practice site, income, and age on levels of job satisfaction among practicing pharmacists. Method: The data consist of responses to a survey questionnaire mailed to a random sample of 5,000 registered pharmacists throughout the United States. A total of 820 individuals mailed back their completed form for a response rate of 16.4 percent. Results: Older, higher-wage earning pharmacists working at independent practice sites experience the greatest amount of job satisfaction. Conclusion: The most significant finding from this study is that age, income, and practice site can predict job satisfaction among practicing pharmacists. Additionally, the results provide empirical evidence for the variables inclusion in future models and they demonstrate the usefulness of Rasch techniques.

\section{INTRODUCTION}

An important issue facing the profession of pharmacy in the United States is the shortage of licensed pharmacists. A report from the United Stated Department of Health and Human Services states that the nation is experiencing a shortage of licensed pharmacists and this trend is expected to continue for years into the future. ${ }^{1}$ This dire warning will require the profession of pharmacy at all levels to focus more closely on voluntary turnover and job satisfaction.

Voluntary turnover is defined as employees who leave an organization at their own discretion. ${ }^{2}$ Research has demonstrated that institutional effectiveness is hindered when turnover decreases job performance. ${ }^{3}$ Similarly, costs of recruiting and training new employees increase. ${ }^{4}$ The relationship between voluntary turnover and job satisfaction is documented. O'Leary et al ${ }^{5}$ discovered that low levels of job satisfaction are predictive of increased levels of voluntary turnover. Within the areas of pharmacy practice, job satisfaction is studied under two directions.

The first angle involves the use of determinants or causal modeling. Under this approach, various facets of job satisfaction are designed to see how well they model or predict job satisfaction. The type of constructs typically associated with job satisfaction include such ideas as job autonomy, workload, and positive affectivity. An example of this approach is Hardigan and Carvajal6 who used structural equation modeling to see how well the Price-Mueller model of job satisfaction predicted job satisfaction among practicing pharmacists. ${ }^{7-8}$ While this type of research oftentimes provides better information about the fundamental nature of job satisfaction, many studies within pharmacy practice focus on demographic determinants.

The second direction of research involves the application of statistical techniques to model the effect of demographic variables to explain job satisfaction. The relationships between demographic variables such as income, age, education, gender, marital status, job categories, and general job satisfaction were studied in pharmacy settings. ${ }^{16,20}$ Analysis demonstrates that females were more satisfied than males when income, age, and education were controlled. Income and age positively affected job

C The Internet Journal of Allied Health Sciences and Practice, 2007 
satisfaction when gender, marital status, and job categories were controlled. Additionally, Carvajal and Hardigan ${ }^{9}$ discovered that $^{\circ}$ when controlling for extrinsic factors (wages or earnings) and intrinsic factors (practice site) women and men exhibit different levels of job satisfaction. While this approach has worked successfully, researchers often confuse the type of measurement used to collect the data (Likert scale) with the appropriate level of measurement.

Likert scales are ordinal measures, and it is incorrect to assume that the intensity of feeling is equivalent with Likert scales. ${ }^{10}$ With ordinal levels, the categories represent an inherent order (more to less), but the numbers assigned to the categories do not indicate the magnitude of difference between the categories. Interval properties imply equally spaced points on a scale where. ${ }^{11}$

1. $a>b>c>d \ldots>k$

2. $a-b=b-c=c-d=\ldots=j-k$

Cohen et al10 argue that it is incorrect to assume that the intensity of feeling between "strongly disagree" and "disagree" is equivalent to the intensity of feeling between other consecutive categories on the Likert scale. The authenticity in assuming an interval scale for Likert-type categories is an important issue, because the appropriate inferential statistics differ for ordinal and interval variables, and if the wrong statistical technique is used, the researcher increases the chance of coming to the wrong conclusion about the significance of his/her research. ${ }^{12}$

Likert scale data can, in principle, be used as a basis for obtaining interval level estimates on a continuum by applying the Rasch Model. Rasch, a type of item response theory, is used in the examination of categorical data. ${ }^{13}$ With this model, raw scores are converted into standardized units. These units are then aligned on a ruler that measures each component of the model. Because Rasch results are linear, independent, objective, and general, inferences can be drawn from them. ${ }^{14}$

Rasch, a form of item response theory, is used in the examination of categorical data. ${ }^{13}$ With this model, raw scores are converted into standardized units. These units are then aligned on a ruler that measures each component of the model. With survey research Likert items are typically analyzed using the rating scale model. The rating scale model is defined as. ${ }^{13}$

$$
P_{n i x}=\frac{\exp \sum_{j=o}^{x}\left[\beta_{n}-\left(\delta_{i}+\tau_{j}\right)\right]}{\sum_{k=o}^{m} \exp \sum_{j=o}^{k}\left[\beta_{n}-\left(\delta_{i}+\tau_{j}\right)\right]}
$$

Where:

$$
\begin{array}{ll}
P_{n i x} & =\text { represents the probability of person } n \text { giving a rating of } x \\
\beta_{n} & =\text { represents the latent trait of person } n \\
\delta_{i} & =\text { represents the difficulty of item } i, \text { and } \\
\tau_{j} & =\text { represents the difficulty of giving a rating category } m
\end{array}
$$

The rating scale model produces measures of a person's latent trait (job satisfaction) on the same scale with measures of item difficulty using a logit scale..$^{13-14} \mathrm{~A}$ logit scale uses the log-odds of obtaining a particular rating to estimate the level of the latent trait and item difficulty. In contrast, traditional statistical analysis treats all items as having equal value and describes data in terms of averages, percentages, and probabilities. ${ }^{13-14}$

The purpose of this study is to investigate the importance of demographic variables in the prediction of job satisfaction among practicing pharmacists through the application of Rasch analysis. The Rasch rating scale model, which converts ordinal data into interval levels of measurement, is applied. The specific hypothesis tested follows:

$\mathrm{H}_{0}$ : The demographic variables gender, ethnicity, practice site, income, and age do not differentiate between levels of job satisfaction among practicing pharmacists.

\section{METHOD}

Using a five-point Likert scale, job satisfaction is measured using five items from the 18-item index developed by Brayfield and

C The Internet Journal of Allied Health Sciences and Practice, 2007 
Rothe. ${ }^{15}$ The validity and reliability of this five-item, global satisfaction index has been demonstrated in previous studies.6-8 Demographic information collected in the survey included the following:

- Gender-Male or Female,

- Ethnicity-Non-Hispanic Black, Asian American, Hispanic, Non-Hispanic White

- Practice site-Adapted from the definitions of the North American Industry Classification System:

- Independent pharmacy is the same as the NAICS "Independent Drug Store," which is one with $\leq 3$ pharmacies.

- Chain Pharmacy is a drug store $\geq 4$ pharmacies (for profit and open to the public). Our definition of "Chain" store includes NAICS "Chain Drug Stores" plus NAICS "Supermarket Pharmacies" and NAICS "Mass Merchant Pharmacies."

- Hospital Pharmacy

- Other refers to pharmacists who work in nursing homes as consultants, and sites not listed above.

- Income-categorized into quartiles for analysis purposes.

- Age—categorized into quartiles for analysis purposes.

Simple random sampling is used to gather the data. A probability sampling method, this technique involves the selection of a sample from a population based on the principle of randomization or chance. Simple random sampling is chosen because each unit's probability of inclusion can be calculated, reliable estimates can be produced along with estimates of the sampling error, and inferences can be made about the population. The data are gathered from responses to a survey questionnaire mailed to 5,000 registered pharmacists throughout the United States whose names and addresses were provided by Medical Marketing Service, a company which maintains a database estimated to include 98 percent of health-related professionals in the country. A postage-free return envelope was provided with the questionnaire.

Because job satisfaction is measured on an ordinal level, Rasch estimation procedures are used to place the construct of job satisfaction on an interval level. With the Rasch model, raw scores are converted into standardized units. ${ }^{13-14}$ These standardized units are called logits (for log-odds unit) and are considered to be interval level measures. ${ }^{13-14}$ The logits have a mean of zero and a standard deviation of one. Scores typically range from -2 to +2 with a higher score indicating more of that trait. For example a pharmacist receiving a zero Rasch score would be at the mean level, a pharmacist with a 1.0 Rasch score would be one standard deviation above the mean or would possess a job satisfaction score higher than the average. A Rasch rating scale model using Winsteps 3.63 .0 is applied to the data. This technique produces scores for each person that can be used in other types of statistical analyses.

Because the Rasch technique converts the ordinal scale scores to interval levels of measurement a generalized linear estimation technique is used to model the independent variables gender, ethnicity, practice site, income, and age on the Rasch dependent variable--job satisfaction score. Here the distribution function is the normal distribution with constant variance and the link function is the identity. The unknown parameters were estimated with maximum likelihood. If significant differences are found in the whole model, linear contrasts are used to identify specific differences. Descriptive statistics are also applied to the data.

\section{RESULTS}

The data consist of responses to a survey questionnaire mailed to 5,000 registered pharmacists throughout the United States. Respondents remained anonymous at all times, so there was no way to ascertain the identity of those who did not reply. A total of 820 individuals mailed back their completed form for a response rate of 16.4 percent. Thirty of these forms were not used due to missing or incomplete information. Thus, the data set analyzed contains 790 observations.

Despite the use of random sampling, the low response rate may appear to be problematic; however, Rasch analysis presents solutions that correct the deficiencies of traditional true score approach. That is, parameters are neither sample nor test dependent, so missing data are not problematic. ${ }^{14}$ Nevertheless, in an effort to ascertain the representativeness of this data set to the original mailing, statistical comparisons were made across two demographic variables: gender and ethnicity. Respondents' distributions did not differ statistically from the original mailing. In an additional effort to bolster external validity, contrasts were made between this study's demographic variables and one recently published study on job satisfaction. ${ }^{16}$ Results show a similar response pattern for the variables gender (males--55\% vs. $56 \%$ ) and for non-Hispanic whites ( $83 \%$ vs. $87 \%$ ).

A study of the survey's psychometric properties was conducted using Rasch techniques. Under Linacre's criteria six criteria are used in the evaluation of rating scale effectiveness. ${ }^{17}$ First, a minimum of ten observations should be in each category. This implies that if category frequencies are low, accurate estimation of Rasch scores can be problematic. Second, the shapes of the probability curves should be peaked for each category. To optimally calculate Rasch scores, a uniform distribution for each

(c) The Internet Journal of Allied Health Sciences and Practice, 2007 
category is necessary (Figure 1-should resemble rolling hills). Third, the average category measures should increase with the rating scale categories. This means that observations in higher categories (i.e., four on the Likert scale) must produce higher measures than observations in lower categories (i.e., two on the Likert scale). Fourth, the OUTFIT mean square statistics should be less than one. The OUTFIT statistic measures explained variance. A score higher than two implies greater noise unexplained variance. Fifth, threshold calibrations should increase with rating scale category. This criterion involves the ability to predict a respondent's score. Essentially, increasing amounts of the underlying variable in a respondent correspond to increasing probabilities of the respondent being observed in higher categories of the rating scale. ${ }^{17}$ Sixth, the category thresholds should be at least 1.4 logits apart and no more than 5 logits apart. This criterion states that from a single item one can infer a particular behavior. Criteria one through five were met and an item reliability measure of one was calculated. Results are presented in Table 1 and Figure 1. Criterion six was not met entirely, but according to Linacre the results represent a close enough approximation. ${ }^{17}$ These results suggest an instrument that adequately measures the latent constructs of job satisfaction.

Figure 1. Model Probability Characteristic Curves Job Satisfaction Study

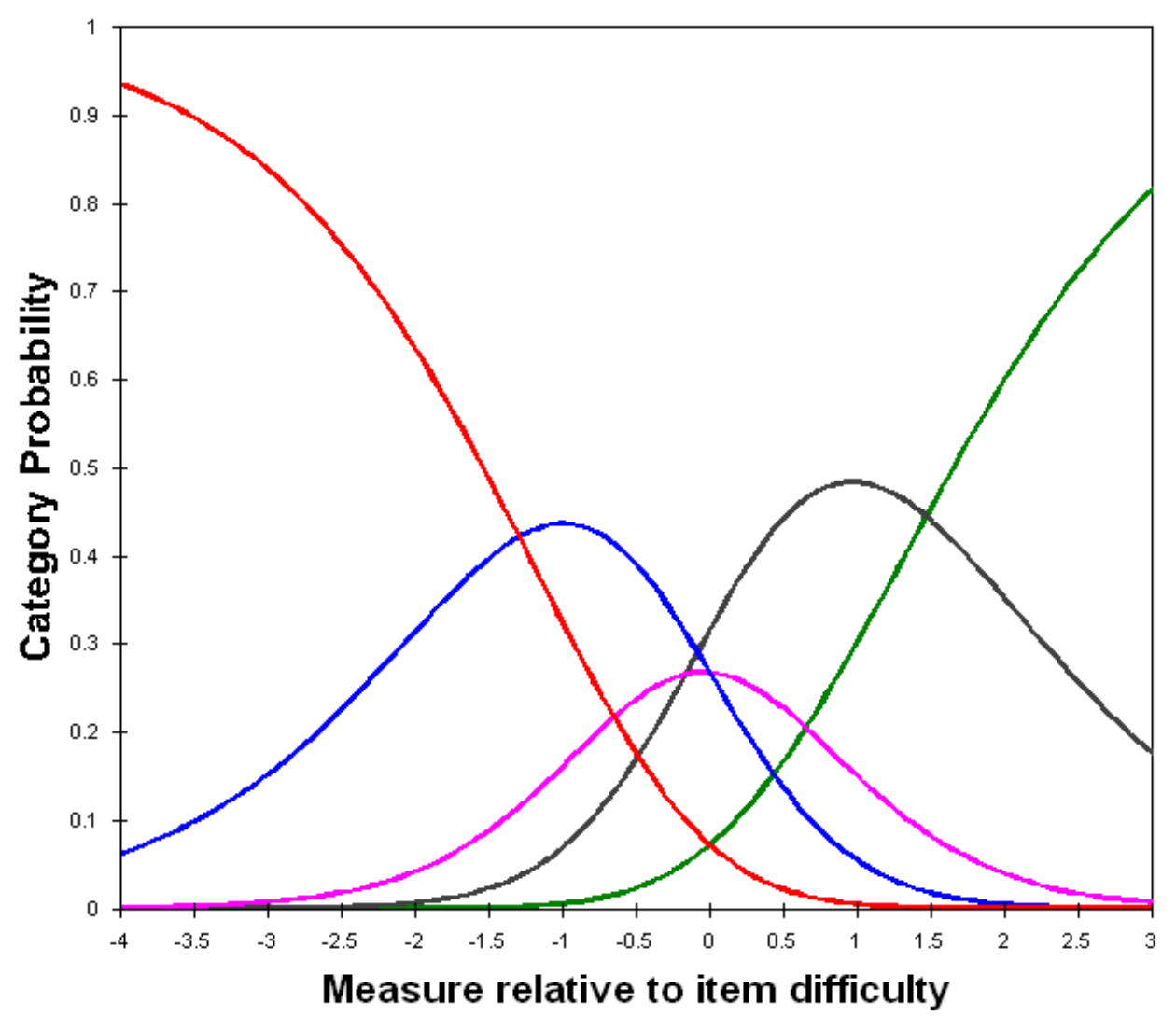

Category Probability: 1 Strongly Disagree (red)

Category Probability: 2 Disagree (blue)

Category Probability: 3 Neither Agree nor Disagree (pink)

Category Probability: 4 Agree (black)

Category Probability: 5 Strongly Agree (green) 
Table 1. Rasch Statistics for Model Variables Construction

\begin{tabular}{|l|l|l|l|l|}
\hline Category Label & $\begin{array}{l}\text { Observed } \\
\text { Count }\end{array}$ & $\begin{array}{l}\text { Average } \\
\text { Measure }\end{array}$ & $\begin{array}{l}\text { OUTFIT } \\
\text { MNSQ }\end{array}$ & $\begin{array}{l}\text { Threshold } \\
\text { Estimate }\end{array}$ \\
\hline 1. Strongly Disagree & 4885 & -0.78 & 1.13 & None \\
\hline 2. Disagree & 10491 & -0.31 & 0.86 & -1.30 \\
\hline 3. Neither Agree nor Disagree & 9426 & 0.03 & .94 & 0.00 \\
\hline 4. Agree & 13954 & 0.41 & 1.00 & 0.17 \\
\hline 5. Strongly Agree & 551 & 0.67 & 1.14 & 1.47 \\
\hline
\end{tabular}

Descriptive statistics reveal that $55 \%$ of respondents are male and $45 \%$ are female. Additional descriptive statistics are found in Table 2. Rasch job satisfaction scores (means and standard deviations) are calculated for each variable in the model and are found in Table 3. All Rasch estimates are above a 2.0 indicating that pharmacists, irrespective of demographic, report high job satisfaction.

Table 2. Demographic Characteristics of Respondents ( $n=790)$

\begin{tabular}{|l|l|c|}
\hline Demographic Characteristics & & Percentage \\
\hline Ethnicity & Non-Hispanic Black & $3 \%$ \\
\hline & Asian American & $7 \%$ \\
\hline & Non-Hispanic White & $83 \%$ \\
\hline Practice Site & Hispanic & $3 \%$ \\
\hline & & $26 \%$ \\
\hline & Independent & $45 \%$ \\
\hline & Chain & $17 \%$ \\
\hline & Hospital & $12 \%$ \\
\hline
\end{tabular}


Table 3. Rasch Estimates of Job Satisfaction by Model Variable

\begin{tabular}{|c|c|c|c|}
\hline & & \multicolumn{2}{|c|}{$\begin{array}{c}\text { Rasch } \\
\text { Satisfaction Score }\end{array}$} \\
\hline & & Mean & Std Dev \\
\hline Gender & $\begin{array}{r}\text { Male } \\
\text { Female }\end{array}$ & $\begin{array}{l}2.47 \\
2.40\end{array}$ & $\begin{array}{l}1.84 \\
1.82\end{array}$ \\
\hline Ethnicity & $\begin{array}{r}\text { Non-Hispanic Black } \\
\text { Asian American } \\
\text { Non-Hispanic White } \\
\text { Hispanic }\end{array}$ & $\begin{array}{l}2.38 \\
2.42 \\
2.47 \\
2.33\end{array}$ & $\begin{array}{l}2.23 \\
2.01 \\
1.83 \\
2.11\end{array}$ \\
\hline Practice site & $\begin{array}{r}\text { Independent } \\
\text { Chain } \\
\text { Hospital } \\
\text { Other }\end{array}$ & $\begin{array}{l}2.99 \\
2.13 \\
2.56 \\
2.27\end{array}$ & $\begin{array}{l}2.10 \\
1.75 \\
1.73 \\
1.37\end{array}$ \\
\hline $\begin{array}{l}\text { Age group } \\
\text { (Quartiles) }\end{array}$ & $\begin{array}{r}21-35 \\
36-45 \\
46-52 \\
53+\end{array}$ & $\begin{array}{l}2.06 \\
2.49 \\
2.51 \\
2.67\end{array}$ & $\begin{array}{l}1.89 \\
1.82 \\
1.76 \\
1.88\end{array}$ \\
\hline $\begin{array}{l}\text { Income (US \$) } \\
\text { (Quartiles) }\end{array}$ & $\begin{array}{r}10,000-67,499 \\
67,500-77,999 \\
78,000-84,999 \\
85,000+\end{array}$ & $\begin{array}{l}2.14 \\
2.19 \\
2.29 \\
2.87\end{array}$ & $\begin{array}{l}2.03 \\
1.83 \\
1.58 \\
1.70\end{array}$ \\
\hline
\end{tabular}

${ }^{*}$ Other refers to nursing home and consultant pharmacists

Results from the generalized linear model show that the variables practice site, age quartile, and income quartile are statistically significant. Specifically, the following differences are found:

- Controlling for respondents' age, ethnicity, income, and age, significant differences exist between practice sites ( $p$ $<.01)$.

- Controlling for respondents' age, ethnicity, practice site, and age, a significant difference is found between income quartiles $(p<.01)$.

- Controlling for respondents' age, ethnicity, practice site, and income, a significant difference is discovered between age quartiles $(p<.01)$.

- Chain pharmacists report the lowest job satisfaction rating while independent pharmacists report the highest. Statistical differences are found between (1) independent and hospital, (2) independent and chain, (3) independent and other, and (4) chain and hospital $(p<.01)$. Figure 2 provides a ruler representing these differences.

- In terms of age, pharmacists in the top age quartile report the highest amount of job satisfaction. Statistical differences are found between pharmacists in the top two age quartiles and those in the fourth quartile $(p<.01)$. No differences are detected between the first, second, and third age quartiles. Figure 2 provides a ruler representing these differences. Essentially, older pharmacists report higher job satisfaction.

- Income differences are also detected. Statistical differences are found between (1) wage quartile 1 and wage quartile 2, (2) wage quartile 1 and wage quartile 3, (3) wage quartile 1 and wage quartile 4, and (4) age quartile 2 and wage quartile 4. Figure 2 provides a ruler representing these differences. The results suggest that higher wage earning pharmacists report higher job satisfaction. 


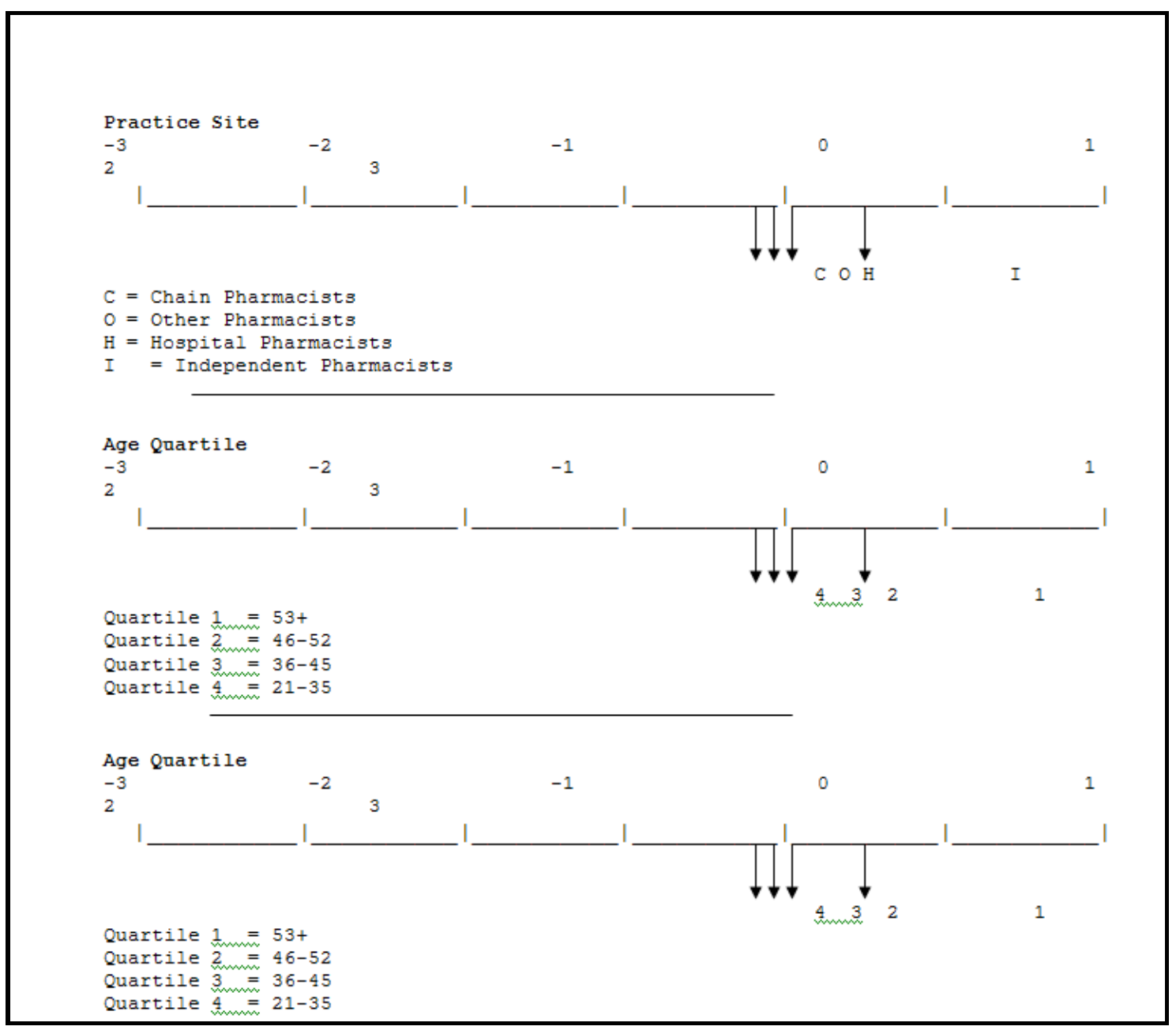

Figure 2. Rasch score by select model variables

Through the application of a Rasch rating scale model, results from the study indicate that older, higher-wage-earning pharmacists working at independent practice sites experience the greatest amount of job satisfaction. This result suggests a rejection of our null hypothesis and indicates that demographical variables, when measured on an interval scale, are capable of differentiating levels of job satisfaction. This also implies that demographical variables can be used in the construction of models of job satisfaction with practicing pharmacists. Specific implications to pharmacy practice follow.

It is established in past research that chain pharmacists report the lowest levels of job satisfaction. Studies that look at various latent predictors of job satisfaction, such as job autonomy and workload, show that chain pharmacists are the least satisfied. 18 Research also demonstrates that independent pharmacists report the highest level of satisfaction and chain pharmacists the lowest. ${ }^{19-20}$

McHugh found that the quality of work life was lower for those in chain settings. ${ }^{21-22}$ Specifically, he discovered that chain pharmacists reported a low perception of being rewarded for their effort and perceived that their practice site failed to provide them with adequate help to perform their job. ${ }^{21-22}$ This is consistent with the findings of Maio et al who argue that more research is needed to investigate work-related factors that affect low levels of job satisfaction in chain settings. ${ }^{19}$

The relationship between job satisfaction and a pharmacist's age is difficult to pinpoint. If the assumption is that older pharmacists have worked for more years in the practice of pharmacy then the results found in this study confirm past research.

C The Internet Journal of Allied Health Sciences and Practice, 2007 
For instance, past research has demonstrated that young practitioners are more likely to be disenchanted because expectations do not meet real world experience. ${ }^{23}$

However, if we assume that age is not related to years-of-experience then the results found here contradict those discovered in a past study. North and Kirk24 found no relationship between age (not years worked) and satisfaction with one's supervisor--a surrogate for job satisfaction. The link between a job supervisor and a level of job satisfaction is not well established, so it is assumed that length in service, as measured by age in this study, is a predictor of job satisfaction.

A relationship between wage or earnings and job satisfaction begins early in a pharmacist's education. Research has demonstrated that a 10 percent rise in earnings increases men's job satisfaction by 3.0 percent and women's job satisfaction by 3.7 percent. ${ }^{25}$ Once pharmacists begin to practice, income again plays a role in their perceived job satisfaction. Research also demonstrates that pharmacists in the 25th wage percentile are less satisfied.26 Furthermore, turnover is also associated with wage earnings. Low pay is the primary reason why pharmacists left small chain or independent pharmacies.22

\section{CONCLUSION}

The most significant finding from this study is that age, income, and practice site can predict job satisfaction among practicing pharmacists. This would seem of practical importance to those designing programs to increase job satisfaction. Additionally, the results provide empirical evidence for the variables inclusion in future models and they demonstrate the usefulness of Rasch techniques. Future research should confirm the findings on an international basis.

The results of this study are limited by bias found in survey research. The relatively low response rate does not appear to affect the study as Rasch analysis is sample independent. Additionally, the sample size is large enough to draw inferences from the Rasch model.

\section{REFERENCES}

1. The Pharmacist Workforce: A Study of the Supply and Demand for Pharmacists. Dept of Health and Human Services, Health Resources and Services Administration, Bureau of Health Professions; December 2000. National Center for Health Workforce Analysis Report.

2. Price JL. A theory of turnover. In: Pettman PO, ed. Labour Turnover and Retention. London, England: Gower Press; 1975:51-75.

3. Dalton DR, Todor WD. Turnover turned over: an expanded and positive perspective. Acad Manage Rev. 1979;4(2):225-235.

4. Alexander JA, Bloom JR, Nuchols BA. Nursing turnover and hospital efficiency: An organization level analysis. Institute for Research on Labor and Employment Working Paper Series. 1991, February 1. Berkley: University of California Press.

5. O'Leary-Kelly, AM, Griffin RW. Job satisfaction and organizational commitment. In: Brewer N, Wilson C, eds. Psychology and policing. Hillsdale, NJ: Lawrence Erlbaum Associates; 1995.

6. Hardigan PC, Lai LL, Carvajal MJ. The influence of positive and negative affectivity on reported job satisfaction among practicing pharmacists. J Pharm Marketing Manage. 2000;13(4):28-32.

7. Price, JL, Mueller, CW. Absenteeism and turnover among hospital employees. Greenwich, Conn: JAI Press; 1986.

8. Price, JL, Mueller, CW. Professional turnover: The case of nurses. Bridgeport, Conn: Luce; 1981.

9. Carvajal MJ, Hardigan PC. Pharmacists' sources of job satisfaction: inter-gender differences in response. Am J Pharm Educ. 2000;64:420-425.

10. Cohen L, Manion L, Morrison K. Research Methods in Education. 5th ed. London, England: RoutledgeFalmer; 2000.

11. Nunnally JC, Bernstein IH. Psychometric Theory. 3rd ed. New York, NY: McGraw-Hill; 1994.

12. Jamieson S. Likert scales: how to (ab)use them. Med Educ. 2004;38(12):1212-1218.

13. Bond TG, Fox CM. Applying the Rasch Model: Fundamental Measurement in the Human Sciences. 3rd ed. Mahwah, NJ: LEA Publishers; 2001.

14. Wright BD, Stone MH. Best Test Design. Chicago, III: MESA Press, 1979.

15. Brayfield, AH, Rothe, HF. An index of job satisfaction. J Appl Psychol. 1951;35(5):307-311.

16. Mott DA, Doucette WR, Gaither CA, Pederson CA, Schommer JC. Pharmacists' attitudes toward worklife: results from a national survey of pharmacists. J Am Pharm Assoc. 2004;44(3):326-336.

17. Linacre, JL. Optimizing rating scale category effectiveness. J Appl Meas. 2002;3(1):85-106.

C The Internet Journal of Allied Health Sciences and Practice, 2007 
18. Hardigan PC, Carvajal MJ. An Application of the Rasch Rating Scale Model to the Analysis of Job Satisfaction Among Practicing Pharmacists. J Am Pharm Assoc. In press.

19. Maio V, Goldfarb NI, Hartman CW. Pharmacists' job satisfaction: variation by practice setting. Pharm Ther. 2004;29(3):184-190.

20. Hassell H. Practice chairman's address: let's get personal---do pharmacists like their work? Pharm J. 2006;277:B17-B19.

21. McHugh PP. Pharmacists' attitudes regarding quality of worklife. J Am Pharm Assoc. 1999;39:667-676.

22. Mott, DA. Pharmacist job turnover, length of service, and reasons for leaving, 1983-1997. Am J Health-Syst Pharm. 2000;57(10):975-984.

23. Noel MW, Hammel RJ, Bootman JL. Job satisfaction and the future of pharmacy. Am J Health-Syst Pharm. 1982;39(4):649-651.

24. North MA, Kirk KW. The pharmacy supervisor and the employee pharmacist's job satisfaction. Am Pharm. 1990;30(5):49-52.

25. Carvajal MJ, Hardigan PC. Estimation of Pharmacy Students' Expected Job Satisfaction Functions: inter-Gender Differences. Am J Pharm Educ. 1999;63:285-289.

26. Ried LD, McGhan WF. An equity model of staff pharmacists' job satisfaction. Journal Pharm Marketing Manage. 1987;1(3):3-24. 